\title{
Difficulties facing first-year medical students at Umm Alqura University in Saudi Arabia
}

\author{
H. Almoallim, ${ }^{1,2}$ S. Aldahlawi, ${ }^{3}$ E. Alqahtani, ${ }^{4}$ S. Alqurashi ${ }^{5}$ and A. Munshi ${ }^{6}$
}

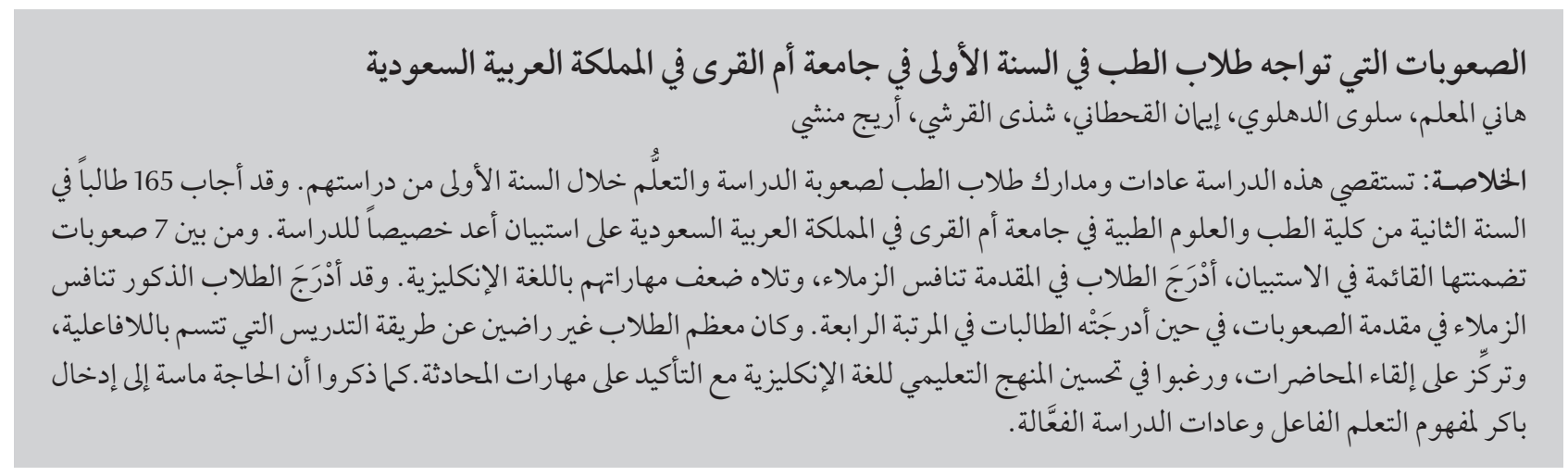

ABSTRACT This study investigated medical students' study habits and perceptions of learning difficulties during their first year of study. A specially-designed questionnaire was answered by 165 second-year medical and medical science students at Umm Alqura University in Saudi Arabia. Out of the 7 difficulties listed in the questionnaire, students ranked peer competition first, followed by poor English language skills. Male students ranked peer competition as the top difficulty whereas females ranked it fourth. A majority of students were dissatisfied with the passive, lecture-based method of teaching and wanted the English language curriculum to be improved by more emphasis on conversation skills. Early introduction of the concept of active learning and effective studying habits is needed.

Difficultés rencontrées par les étudiants en première année d'études de médecine à I'Université Umm AlQura (Arabie saoudite)

RÉSUMÉ Le présent travail de recherche a analysé les habitudes d'étude des étudiants en médecine et leur perception des difficultés d'apprentissage pendant leur première année d'étude. Un questionnaire spécialement conçu a été administré à 165 étudiants de deuxième année de la faculté de médecine et de sciences de l'Université Umm Al-Qura, (Arabie saoudite). Sur les sept difficultés répertoriées dans le questionnaire, les étudiants ont classé la compétition entre étudiants en premier, puis de médiocres compétences linguistiques en anglais en second. Les étudiants de sexe masculin ont classé la compétition entre étudiants comme la première difficulté, alors que les étudiantes ne l'ont classée que quatrième dans la liste. Pour la majorité, les étudiants n'étaient pas satisfaits de la méthode d'enseignement passive reposant sur les cours magistraux et souhaitaient que le programme d'enseignement en langue anglaise soit amélioré, en mettant davantage l'accent sur le développement des compétences à l'oral. II est nécessaire d'introduire tôt dans le cursus le concept d'apprentissage actif et des habitudes d'étude efficaces.

'Department of Medicine, Medical College, Umm Alqura University, Saudi Arabia (Correspondence to H. Almoallim: hanialmoallim @hotmail.com).

${ }^{2}$ Department of Medicine, King Faisal Specialist Hospital, Jedda, Saudi Arabia.

${ }^{3}$ Department of Dentistry, International Medical Center, Jedda, Saudi Arabia

${ }^{4}$ Department of Radiology; ${ }^{6}$ Department of Family Medicine, National Guard Hospital. Jedda, Saudi Arabia.

${ }^{5}$ Department of Internal Medicine, Al-Hada Armed Forces Hospital, Taif, Saudi Arabia.

Received: 30/03/09; accepted: 17/06/09 


\section{Introduction}

The relevance of an educational programme is a concern for curriculum designers. Lack of interest and increased stress levels are typical problems faced by students when they perceive courses as lacking in relevance to their studies. Learning interventions that are directly based on students' needs, promote student participation, and are largely student-driven have been shown to enhance students' performance [1].

Students enter the medical college of Umm Alqura University in Saudi Arabia directly from high school at an average age of 18 years. The school system relies mainly on teacher-based activities, examinations based on regurgitation of memorized information and norm-referenced tests to evaluate students. As a result, most of the students acquire passive learning habits. The secondary school system in Saudi Arabia uses the Arabic language as the primary language for education; English is taught as a second language, starting in grade 7 . As the medical school curriculum is taught in English, all first-year students, regardless of their language proficiency level, receive an intensive course in English along with their other premedical requirements.

When they join university students are faced with increased academic demands and quickly realize that theyneed to develop appropriate learning skills. Many capable medical students experience frustration and failure [2]. While introductory learning skills courses are common in many international medical schools, few medical schools in the Middle East have such courses. At Umm Alqura University we planned to design a learning skills course for our first-year students of medicine and medical sciences to introduce the principles of active learning. To inform the design of the course, we surveyed second-year medical and medical science students about the difficulties they faced during their first year and their study habits.

\section{Methods}

All second-year medical and medical sciences students (graduation class 2009) in Umm Alqura University, Mecca, Saudi Arabia were asked to answer a questionnaire designed by the authors. A total of 270 students were surveyed in October 2006 (128 males and 142 females), comprising 153 medical students and 117 medical science students.

In the first part of the questionnaire, students were presented with a list of 7 common difficulties faced by students and asked to rank them according to the degree of difficulty they faced in their first year, from 1 (most difficult) to 7 (least difficult). The items were based on the results of interviews with a group of medical students from different classes carried out by the authors. The second part was divided into questions about learning styles and study habits: their own beliefs about the difficulty and workload of the first-year course (3 items); difficulties they experienced with aspects of the first-year course (8 items); how they communicated with instructors during teaching sessions (4 items); what self-study strategies would facilitate their learning (3 items); and ways in which the university could organize courses to facilitate learning (9 items). Students were asked to answer each statement as yes, no or don't know. Two open-ended questions about additional difficulties were included. All questions were in English.

A pilot sample of medical students evaluated the simplicity of the questionnaire language and the time needed to answer it and adjustments were made based on their recommendations. The questionnaire was distributed to second-year students after their classes. Students were asked to answer and return it immediately to one of the supervisors. Most students needed around 30 minutes to complete the questionnaire.
The data were entered in Microsoft Excel software and the Student $t$-test was used to assess significant differences based on sex. $P$ value $<0.05$ was considered significant.

\section{Results}

Of the 270 students surveyed, 165 responded (89 females and 76 males; 119 medical students and 46 medical science students). The overall response rate was therefore $61 \%$ (62\% among females and 59\% among males). More students of medicine responded (78\%) than medical science students (39\%).

A majority of students considered peer competition to be the greatest difficulty facing them in the first year (mean rank 4.28 out of 7) (Figure 1). English language skills were rated second (mean rank 3.95). Difficulty of the subjects was ranked third (mean rank 3.78), followed by lack of information resources (mean rank 3.76) and the large amount of academic work (mean rank 3.70). Lack of time for social life (mean rank 3.13) and stress related to courses (mean rank 2.77) were the lowest ranked items.

When analysing the data by sex, peer competition was ranked first as a difficult faced by male students (mean rank 5.17) whereas female students ranked it fourth (mean rank 3.52) ( $P$ $<0.05$ ) (Figure 2). On the other hand, English language was ranked first as a difficulty by female students (mean rank 4.09). More female students than male students felt they were facing a high academic workload (mean ranks 4.01 and 3.33 respectively) $(P<0.05)$. Furthermore, more male students than female students thought the subjects were too difficult (mean ranks 4.16 and 3.45 respectively) $(P<0.05)$.

Half of the students (51\%) agreed that the courses taught in the first year were hard, $61 \%$ that the courses were time-consuming and $47 \%$ that their results did not reflect the amount of 


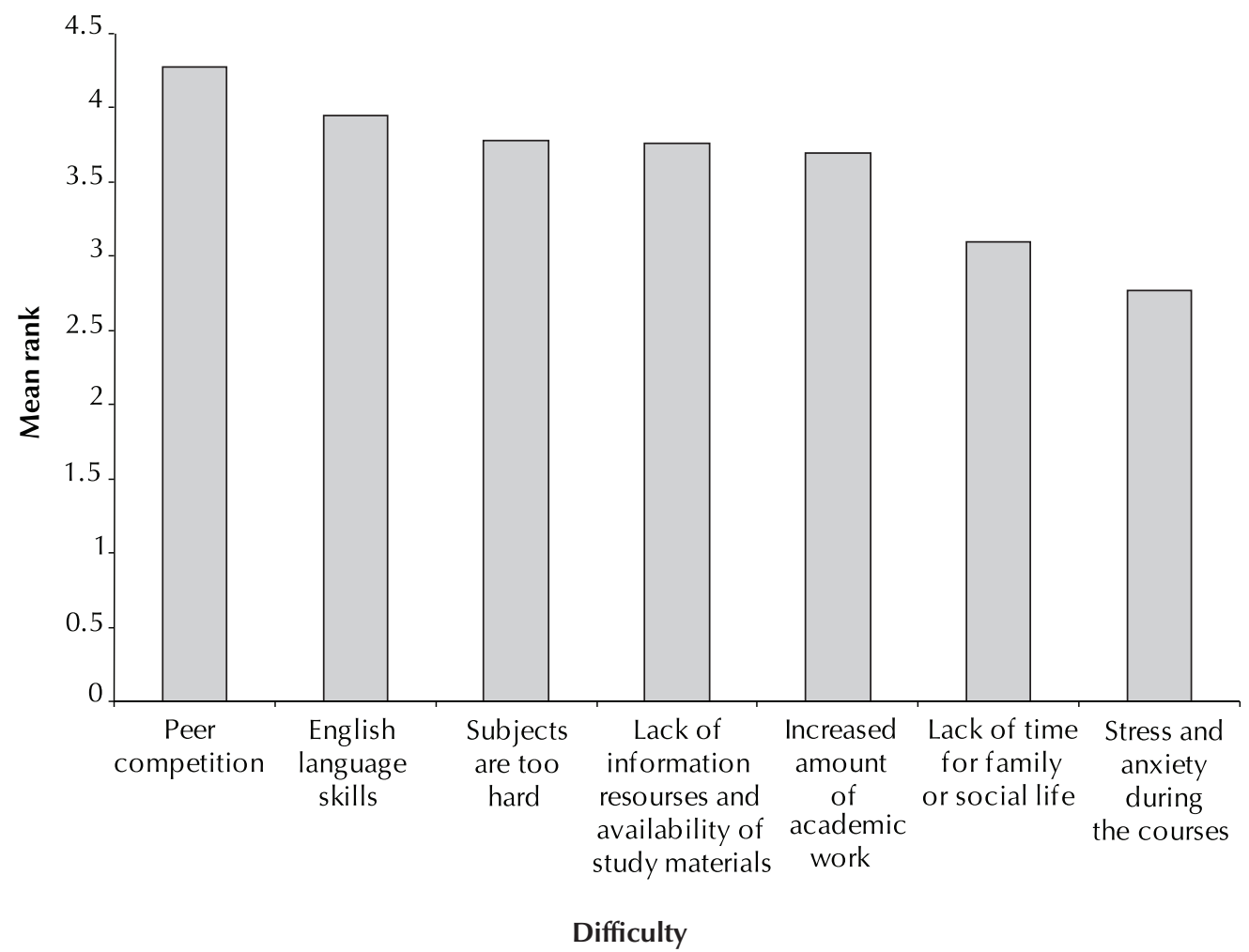

Figure 1 Mean ranking of 7 difficulties facing medical and medical sciences students during first-year medical school ( $n=165$ students)

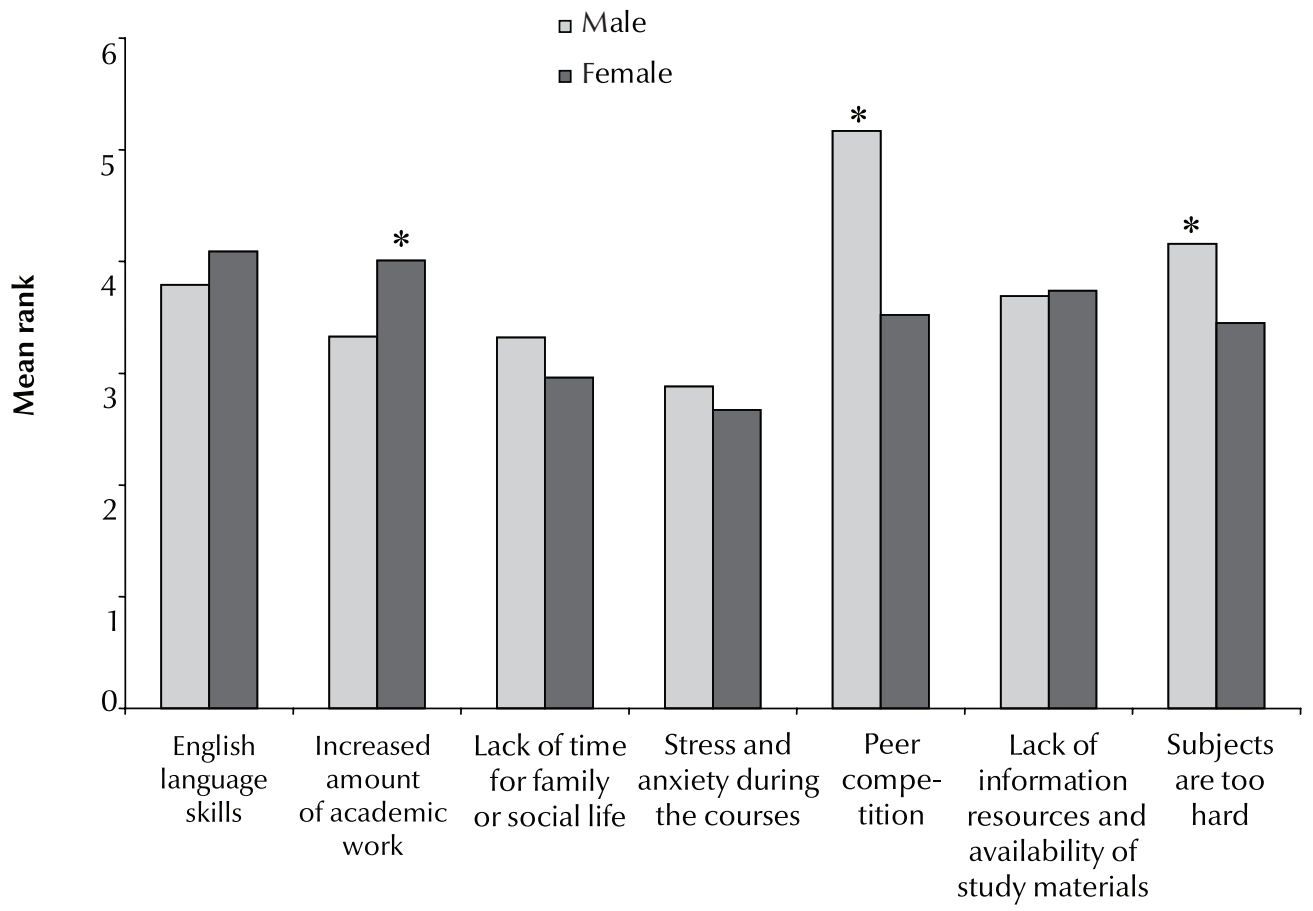

Difficulty

Figure 2 Mean ranking of difficulties facing male and female medical and medical sciences students in first-year of medical school ( $n=76$ males; $n=89$ females). *Statistically significant differences were found between males and females regarding peer competition, increased academic demands and subjects are too hard $(P<0.05)$ 
effort they put into their study. There were no statistical differences between the sexes (data not shown). Regarding problems they faced during teaching sessions including lectures, $62 \%$ of the students agreed that they had difficulty following the instructors and taking notes and 50\% did not know what they were expected to learn by the end of teaching sessions. Concerning their assessments, $60 \%$ of the students had difficulty remembering information and writing essays and $40 \%$ had problems with answering multiple choice questions. More female students than male students reported difficulty in keeping up with the required reading and in remembering information $(P<0.05)$ (data not shown).

Just over half of the students (52\%) had problems with communicating and explaining their ideas during teaching sessions, 52\% did not ask questions or interact with instructors, $53 \%$ considered themselves shy, while $46 \%$ asked instructors if they did not understand something. Male students were signifcantly more likely than females to ask for help from instructors when they faced difficulties $(P<0.05)$ (data not shown).

Regarding the strategies that students followed to facilitate their learning, 59\% reported that they did not prepare for teaching sessions by reading about the subject in advance and 56\% did not search for information to supplement teaching sessions. However, $86 \%$ would use the library resources to facilitate learning. More male students than females would prepare for teaching sessions by reading about the subject $(P$ $<0.05$ ) (data not shown).

The majority of the students (85\%) agreed that they would like an introductory course prior to the start of first year medical school and $80 \%$ would welcome a mentor assigned to each student. A majority also wanted instructors to give more time for discussion and answering questions (80\%) and to clarify the learning outcomes of each teaching session (80\%). Many wanted more feedback on their own performance $(75 \%)$ and $74 \%$ wanted to be divided into smaller groups during teaching sessions. More than half of the students wanted a different approach to teaching than lectures $(60 \%)$ and more help with using library and online services (55\%); $60 \%$ agreed that extracurricular activities would help to bond students and instructors.

Several suggestions resulted from analysing open-ended questions. A majority of students thought that the English language curriculum should be improved, with more emphasis on conversation skills. First-year course instructors should speak both Arabic and English languages. A majority of students were dissatisfied with the passive, lecture-based and traditional way of teaching; they wanted to be involved in the learning process and to have more chance to ask questions during teaching sessions.

\section{Discussion}

Needs analysis can be used to identify problems in the educational process. Learners remain a valuable resource that should be utilized by curriculum planners to diagnose problems in course design and delivery. The findings of this study will help us to design a learning skills course that should meet the needs of our students.

Learning skills courses are intended to prepare students to cope with the new learning environment in medical colleges and its challenges. Significant numbers of first-year medical students report little experience, particularly in IT skills and library research [3]. Essay writing and oral presentation are also rarely practised [3]. Students in the majority of medical schools in the Middle East are left alone to face this new, challenging environment. Inability to cope with these changes leads to a high drop-out rate from courses. Even at higher levels, the causes of academic failure are widespread and range from deficient learning skills to financial, domestic and emotional problems [4]. A great majority $(85 \%)$ of our students recognized the importance of introducing a learning skills course that would help in the transitional phase to meet the challenges of university life. Most of them $(80 \%)$ also recognized the need to provide a proper mentoring programme in the college to help students overcome their academic problems.

Students in this study considered peer competition to be the top difficulty facing them in the first year. The assessment process in their schools was probably focused on comparisons between students rather than specific achievement levels. This has resulted in the overwhelming concern of our students being the performance of their peers. In contrast, a review of stress in undergraduates noted that peer competition was one of the least common sources of stress among undergraduates [5]. Our medical college therefore needs to implement strategies to solve this problem. Developing valid and reliable assessment methods and enhancing the educational environment [6] are probably initial steps.

Lack of fluency in the language of instruction can form a barrier to medical education [7]. It has been reported that many nurses from non-English speaking backgrounds are at high risk of failure in university programmes [8]. Few studies have investigated clinical experiences of students from non-English speaking backgrounds and strategies to support their learning. In an Australian university unsatisfactory spoken language fluency was associated with poor performance in medical communication skills under examination conditions [9]. English was considered one of the top difficulties facing our students during their first year. Students clearly felt the need for an improved English language curriculum in our college with more focus on conversation skills. They also suggested that 
first-year instructors must speak both Arabic and English languages. In another Australian study, medical students experiencing English language difficulties were allocated to a faculty-based language development programme for up to 2 years [10]. Similar approaches can be adopted in our college.

Stress is common among medical students. The one-month prevalence of mental distress among medical students in one college in Ethiopia was found to be $32.6 \%$ [11]. The same study showed that the risk of mental distress decreased in the students' later years of medical school. Other studies suggested that stress and anxiety are major causes of cognitive dysfunction and poor academic performance in university students $[12,13]$. Another study linked anxiety in medical students to the medical curriculum [14]. Students with high test anxiety are compromised in their performance and emotional wellbeing [15]. It was shown that mental health worsens after students begin medical school and remains poor throughout training $[16,17]$. Great care should be taken to avoid any factors that may increase students' stress levels.

Our students experienced substantial problems with the traditional teaching methods at this college, including lectures. A majority of them had difficulty in following instructors and taking notes during lectures. This could partly be explained on the basis of deficiencies in basic learning skills such as listening and note-taking. However, the fact that half of students did not understand the objectives of their lectures is clearly likely to compromise the effectiveness of these lectures. It is not surprising therefore that more than $60 \%$ of our students thought that the subjects taught in the first year were time-consuming. As long ago as the 1970s there was evidence of students' dissatisfaction with unchallenging lectures [18] and that student concentration in lectures rose sharply to reach a maximum after 10-15 minutes and fell steadily thereafter [19]. Nevertheless many medical colleges still use traditional methods of teaching.

An interesting finding in our study was that a majority of our students considered themselves to be shy: 53\% reported never asking questions or interacting with instructors during lectures. Only 46\% would interact if they did not understand something. Passive learning is an expected outcome with large-group teaching formats [20]. Active participation of learners in any learning intervention is a key factor for effective learning. Ourstudents' perceptions of the learning process needs to be changed. They need to be oriented to the concepts of deep and superficial approaches to learning. A majority of our students did not prepare in advance for their lectures and tended not to seek information beyond what was mentioned during lectures. These are classic examples of a superficial approach to learning.

The results of studies on gender differences in the experiences of medical students vary. A study in India concluded that stress did not vary significantly based on sex [21]. In an Iranian study, stress was associated with female sex [22] and in a study in Austria male sex was one of the factors that contributed to academic success in medical students [23]. In our study, significantly more female students were concerned about the academic workload than were males. They found more difficulties in keeping up with the required reading and in remembering information. Males on the other hand were more concerned about peer competition. In one study, academic factors were the highest perceived cause of stress in medical students regardless of sex [21].

There are some limitations to our study. It was based on self-reporting which may be a source of bias in the responses. The study was carried out in only one medical college in Saudi Arabia so the results cannot be generalized to other medical colleges. Nevertheless the study does shed some light on issues related to first-year medical students studying medicine in English language.

Medical colleges in Saudi Arabia should consider needs analysis studies to inform changes in educational strategies. Learning skills courses are clearly desired by our students. These courses should prepare Saudi medical students to overcome difficulties facing them such as peer competition. These courses should also build active study skills and develop a deep approach to learning. Based on our findings, the English language curriculum requires revision and new teaching methods should be employed.

\section{References}

1. Beckert L, Wilkinson TJ, Sainsbury R. A needs-based study and examination skills course improves students' performance. Medical Education, 2003, 37:424-428.

2. Durak $\mathrm{HI}$ et al. Description and evaluation of an innovative course on learning and study skills for the first year medical students. Tohoku Journal of Experimental Medicine, 2006, 210:231-237.

3. Whittle SR, Murdoch-Eaton DG. Lifelong learning skills: how experienced are students when they enter medical school? Medical Teacher, 2004, 26:576-578.
4. Whittle SR, Eaton DG. Attitudes towards transferable skills in medical undergraduates. Medical Education, 2001, 35:148-153.

5. Ko SM, Kua EH, Fones CS. Stress and the undergraduates. Singapore Medical Journal, 1999, 40:627-30.

6. Al-Hazimi A et al. Educational environment in traditional and innovative medical schools: a study in four undergraduate medical schools. Education for Health (Abingdon, England), 2004, 17:192-203.

7. Chur-Hansen A, Barrett RJ. Teaching colloquial Australian English to medical students from non-English speaking backgrounds. Medical Education, 1996, 30:412-417. 
8. Rogan F et al. 'You find yourself.' Perceptions of nursing students from non-English speaking backgrounds of the effect of an intensive language support program on their oral clinical communication skills. Contemporary Nurse, 2006, 23:72-86.

9. Chur-Hansen A, Vernon-Roberts J, Clark S. Language background, English language proficiency and medical communication skills of medical students. Medical Education, 1997, 31:259-263.

10. Chur-Hansen A. Language background, proficiency in English, and selection for language development. Medical Education, 1997, 31:312-319.

11. Alem A et al. Mental distress in medical students of Addis Ababa University. Ethiopian Medical Journal, 2005, 43:159-166.

12. Akgun S, Ciarrochi J. Learned resourcefulness moderates the relationship between academic stress and academic performance. learned resourcefulness moderates the relationship between academic stress and academic performance. Educational Psychology, 2003, 23:287-294.

13. McKenzie K, Schweitzer R. Who succeeds at university? Factors predicting academic performance in first year Australian university students. Higher Education Research and Development, 2001, 20:21-33.

14. Smith CK et al. Depression, anxiety, and perceived hassles among entering medical students. Psychology, Health and Medicine, 2007, 12:31-39.

15. Schaefer A et al. Seelische Gesundheit und Studienerfolg von Studierenden der Medizin mit hoher und niedriger Prufung- sangstlichkeit [Mental health and performance of medical students with high and low test anxiety]. Psychotherapie, Psychosomatik, Medizinische Psychologie, 2007, 57:289-297.

16. Dyrbye LN, Thomas MR, Shanafelt TD. Medical student distress: causes, consequences, and proposed solutions. Mayo Clinic Proceedings, 2005, 80:1613-1622.

17. Dutta AP, Pyles MA, MiederhoffPA. Stress in health professions students: myth or reality? A review of the existing literature. Journal of National Black Nurses' Association, 2005, 16:63-68.

18. Shephard RJ, Ashley MJ. Attitudes of health science students towards teaching practices, examinations, and other related issues. Medical Education, 1979, 13:111-116.

19. Stuart J, Rutherford RJ. Medical student concentration during lectures. Lancet, 1978, 2:514-516.

20. Cantillon P. Teaching large groups. British Medical Journal, 2003, 326:437.

21. Supe AN. A study of stress in medical students at Seth G.S. Medical College. Journal of Postgraduate Medicine, 1998, 44:1-6.

22. Shariati M, Yunesian M, Vash JH. Mental health of medical students: a cross-sectional study in Tehran. Psychological Reports, 2007, 100:346-354.

23. Frischenschlager O, Haidinger G, Mitterauer L. Factors associated with academic success at Vienna Medical School: prospective survey. Croatian Medical Journal, 2005, 46:58-65.

\section{Operational research in tropical and other communicable diseases: final report summaries 2007-2008}

Operational research is crucial for identifying ways to increase access to timely diagnosis and effective treatment. It involves the evaluation of programme implementation, leading to improved policy-making, better design and operation of health systems, and more efficient methods of service delivery. The Regional Office for the Eastern Mediterranean supports operational research in tropical and other diseases through the UNICEF/UNDP/World Bank/WHO Special Programme for Research and Training in Tropical Diseases (TDR) supported Small Grants Scheme. The scheme encourages collaboration between national control programmes and researchers from academia. The aim of the series is to disseminate the results of the operational research projects supported by the scheme with the ultimate goal that they are translated into the policies and practices of national control programmes The report is available in English and can be downloaded at: http://www.emro.who.int/publications/Book_Details. asp? ID = 1040 . 